\title{
CDISC SDTM Cardiovascular Findings About Test Code Terminology
}

National Cancer Institute

\section{Source}

National Cancer Institute. CDISC SDTM Cardiovascular Findings About Test Code

Terminology. NCl Thesaurus. Code C119015.

Terminology associated with the cardiovascular findings about test codes codelist of the Clinical Data Interchange Standards Consortium (CDISC) Study Data Tabulation Model (SDTM). 